\title{
PENGARUH PENAMBAHAN LATIHAN CORE STABILITY TERHADAP PENINGKATAN NILAI KESEGARAN JASMANI B PADA PRAJURIT
}

\author{
Wita Hana Puspita ${ }^{1)}$, Tjetjep Sudrajat ${ }^{2)}$ \\ 1) Universitas Negeri Sebelas Maret, Jakarta, Indonesia \\ ${ }^{2)}$ Detasemen Kesehatan Lapangan, Jakarta, Indonesia \\ Email:wita.tj0408@gmail.com
}

\begin{abstract}
Abstrak
Seorang prajurit TNI AD harus dapat membina kesegaran jasmani agar tubuhnya menjadi sehat dan dapat melakukan tugas pokok untuk menjaga kedaulatan serta keutuhan wilayah NKRI. Penelitian ini bertujuan untuk mengetahui pengaruh penambahan latihan core stability terhadap peningkatan nilai kesegaran jasmani B pada prajurit. Penelitian desain kuasi eksperimental dilaksanakan di Yon Armed 4 Cimahi. Sampel sebanyak 20 prajurit dibagi menjadi 2 kelompok. Variabel dependen adalah skor kesegaran jasmani B dan variabel independen adalah latihan core stability. Latihan dilaksanakan selama 4 minggu dengan frekuensi 3x per minggu. Perbedaan hasil tes antar kelompok eksperimen dan kelompok kontrol baik sebelum dan sesudah latihan core stability diuji dengan independent $T$ test. Terdapat perbedaan Mean skor kesegaran jasmani antara kelompok eksperimen $($ Mean= 85.80; $\mathrm{SD}=2.82)$ dan kelompok kontrol $($ Mean= 82.50; $\mathrm{SD}=2.32)$ sebelum intervensi, dan perbedaan tersebut secara statistik signifikan $(\mathrm{p}=0.011)$. Terdapat perbedaan selisih skor kesegaran jasmani sebelum dan sesudah intervensi antara kelompok eksperimen (Mean=3.90; $\mathrm{SD}=1.52)$ dan kelompok kontrol (Mean=1.60; $\mathrm{SD}=0.70)$ dan secara statistik signifikan $(\mathrm{p}<0.001)$, dengan effect size $=1.94$. Kesimpulan latihan core stability efektif untuk meningkatkan nilai kesegaran jasmani B pada prajurit Yon Armed 4 Cimahi.
\end{abstract}

Kata kunci: Latihan core stability, kesegaran jasmani, latihan

\section{Abstract}

An Army soldier must be able to foster physical fitness so that his body becomes healthy and can carry out his main duties to maintain the sovereignty and territorial integrity of the Republic of Indonesia. This study aims to determine the effect of adding core stability exercise to increasing the value of physical fitness $B$ in soldiers. Quasi experimental design research held at Yon Armed 4 Cimahi. A sample of 20 soldiers divided into 2 groups. The dependent variable is the physical fitness score $B$ and the independent variable is the core stability exercise. Exercise is carried out for 4 weeks with a frequency of 3 times per week. The difference in test results between the experimental group and the control group 
both before and after core stability exercise was tested by independent $T$ test. There was a difference in the mean physical fitness scores between the experimental group (Mean $=85.80 ; S D=2.82)$ and the control group (Mean= 82.50; $S D=2.32$ ) before the intervention, and the difference was statistically significant $(p=0.011)$. There was a difference in physical fitness scores before and after the intervention between the experimental group (Mean= 3.90; $S D=$ $1.52)$ and the control group (Mean $=1.60 ; S D=0.70)$ and statistically significant $(p<0.001)$, with effect size $=1.94$. Conclusion core stability exercise is effective to increase the physical fitness value of B on soldiers of Yon Armed 4 Cimahi.

Keywords: Core stability exercise, physical fitness, Exercise

Diterima: 08-11-2021_Direvisi: 15-12-2021_Diterbitkan: 20-12-201

\section{Pendahuluan}

Dalam organisasi TNI AD seorang prajurit harus dapat membina jasmaninya agar tubuhnya menjadi sehat dan dapat melakukan pekerjaan dengan baik, kesegaran jasmani merupakan salah satu peran penting dalam penyelenggraan, pembentukan, peningkatan, dan pemeliharaan jasmani militer baik perorangan maupun satuan dilaksanakan secara maksimal, agar terwujud kondisi jasmani yang prima yang diperlukan guna mendukung pelaksanaan tugas pokok dalam menjaga kedaulatan serta keutuhan wilayah daratan Negara Kesatuan Republik Indonesia dan untuk mempertinggi daya tempur dalam pengamana wilayah konflik (Putra, 2013).

Untuk mewujudkan kualitas fisik yang prima tersebut pembinaan jasmani dilaksanakan secara periodik, sistimatis dan terpadu meliputi pengukuran postur tubuh yang harmonis sehingga dapat memenuhi tuntutan tugas, tes kesegaran jasmani (kesegaran A lari 12 menit dan kesegaran B terdiri dari pull-up, sit-ups, push-ups, shutle run 6x10 meter) sehingga dapat memenuhi terciptanya daya tahan tubuh yang prima, dan tes ketangkasan jasmani (halang rintang, lintas medan, kecepatan mars, ketahanan mars, mountainering, loncat kendaraan, renang militer, beladiri militer, cross country dan lainlain) sehingga dapat memenuhi terwujudnya kerja otot tubuh yang maksimal (Jamalong, 2016).

Pembinaan kesegaran jasmani setiap hari di satuan diberikan latihan yang teratur seperti senam pagi bersenjata dengan beban senjata 4,2 kg dilanjutkan dengan kegiatan lari bersenjata selama 30 menit dilaksanakan 3 kali dalam seming- gu dengan beban senjata. Sehingga dalam kegiatan ini mengakibatkan terjadinya pembinaan fisik yang maksimal (Pratama, 2014).

Pembina kesegaran jasmani perajurit harus memperhatikan atau menjaga faktorfaktor yang mempe- ngaruhi kesegaran jasmani (umur, tenaga, jenis serat otot, dan daya tahan) agar fisik dan jasmani setiap prajurit proporsional dan tidak mengalami kelelahan dalam menjalankan tugas pokok seorang prajurit.

Untuk hal tersebut diperlukan suatu latihan yang bersifat teratur dan terarah sehingga perlu memahami dosis latihan pada program latihan yang diberikan. Latihan 
yang telah diberikan dan penambahan latihan core stability dengan menggunakan otototot punggung dan perut secara ritmis dan kontinyu, sehingga akan meningkatkan kekuatan otot dan memberikan dasar yang kokoh dimana semua otot dapat bekerja untuk memenuhi gerakan dalam merangsang kemampuaan fungsi stabilitas postur dan mobility (fungsi gerak) sehingga dapat mencegah cedera dan meningkatkan performa prajurit (Utami, 2015).

Latihan core melalui beberapa pendekatan seperti daya tahan otot inti (core endurance), stabilitas inti (core stability) dan latihan kekuatan inti (core strength training). Ketiga komponen tersebut memiliki perannya masing-masing yaitu kemampuan untuk mempertahankan posisi atau melakukan banyak pengulangan, kapasitas sistem stabilitas untuk memelihara zona netral intervertebralis dalam batasan fisiologis dan kekuatan inti sebagai kemampuan otot-otot untuk menghasilkan kekuatan melalui kekuatan kontraksi dan tekanan intraabdominal (Saeterbakken et al., 2015).

Pemberian latihan core stability dengan tujuan untuk mempertahankan daya tahan otot rangka (good stability good mobility), dengan memperhatikan core stability dalam setiap gerakan latihan jasmani, maka kita dapat memelihara postur dengan baik dalam melakukan gerakan serta menjadi dasar untuk semua gerakan pada lengan dan tungkai dengan stabilitas postur, karena core stability menggambarkan kemam- puan untuk mengontrol atau mengen- dalikan posisi dan gerakan sentral pada tubuh diantaranya head and neck alignment, alignment pada vertebral, column thorax dan pelvis stability/mobility dan ankle and hip strategis (Az-Zahra et al., 2016).

Penelitian sebelumnya tentang hubungan antara ketahanan otot core stability dan keseimbangan statis untuk kemampuan menembak prajurit militer oleh Nourizadeh et, al tahun 2019 hasil uji statistik menunjukan ada korelasi signifikan antara rerata skor menembak dengan catatan total otot core stability, dan korelasi antara keseimbangan statis dan catatan tes ketahanan otot core stability (Nourizadeh et al., 2019).

Penelitian selanjutnya yang telah dilakukan terhadap otot-otot core stability secara sistematis meninjau literatur terkini tentang aktivitas elektromiografi pada enam otot inti (rektus abdominis/RA, oblik internal/IO dan eksternal/EO, transversus abdominis/TA, lumbar multifidus/MUL, dan erector spinae/ES) selama latihan kebugaran fisik inti pada orang dewasa yang sehat. Studi ini secara sistematis meninjau literatur terkini tentang aktivitas EMG di enam otot inti selama latihan kebugaran fisik inti. Aktivitas terbesar pada otot RA, EO, dan ES ditemukan pada latihan beban bebas. Aktivitas IO terbesar ditemukan pada latihan core stability (plank, roll out, dll) sedangkan latihan tradisional (push up, curl up, dll) menunjukkan aktivasi MUL terbesar (OlivaLozano et al., 2020).

Penelitian oleh Iskandar menunjukan bahwa pelatihan core stability dapat meningkatkan daya tahan, keseimbangan statis, dan lari pada atlet di perguruan tinggi. Penelitian yang penulis lakukan menggunakan skor kesegaran jasmani B yang dikeluarkan oleh Dinas Jasmani TNI AD Indonesia untuk mengukur tingkat kesegaran jasmani pada prajurit di Indonesia (Iskandar, 2016). Oleh sebab itu tujuan dari penelitian 
ini adalah apakah ada pengaruh penambahan latihan core stability pada prajurit di Yon Armed 4 Cimahi, dalam rangka peningkatan nilai kesegaran jasmani prajurit.

\section{Metode penelitian}

Penelitian ini dilaksanakan di Yon Armed 4 Cimahi pada bulan Maret 2012. Sampel diambil dari satu regu yang terdiri dari 20 orang prajurit yang memenuhi kriteria inklusi yaitu: usia 20-30 tahun, berat badan $65-75 \mathrm{~kg}$, tinggi badan $160-175 \mathrm{~cm}$, kondisi sehat jasmani dan rohani. Kriteria eksklusi yaitu: sedang dalam kondisi tidak sehat atau dalam masa pengobatan, keadaan cedera atau gangguan (pada lengan, tubuh, tungkai), berat badan diatas $80 \mathrm{~kg}$, usia diatas 35 tahun.

Desain penelitian kuasi eksperimental dengan sampel berjumlah 20 orang yang dibagi ke dalam 2 kelompok. Kelompok eksperimen sebanyak 10 prajurit menerima Latihan kesegaran jasmani B biasa (sit-up, push-up, pull-up, shuttle run) ditambah dengan latihan core stability (plank, side plank, crunch, twist sit-up), dan kelompok kontrol menerima hanya latihan kesegaran jasmani B biasa (sit-up, push-up, pull-up, shuttle run). Latihan diberikan dan dipantau selama 4 kali seminggu dan frekuensi 3 kali per minggu.

Latihan core stability dilakukan sebanyak 10 repetisi tiap gerakan, istirahat 60 detik sebelum dimulai pada set berikutnya, pengulangan 3 set tiap latihan, dengan durasi latihan 45 menit terdiri dari pemanasan 10 menit dan pendinginan 5 menit setelah latihan inti. Alat-alat yang digunakan adalah stopwatch, papan penilaian, dan formulir penilaian.

Variabel dependen adalah skor kesegaran jasmani B range 0-100 yang ditetapkan oleh Dinas jasmani TNI AD dan variabel independen adalah latihan core stability. Analisis statistik menggunakan independent T-test dengan membandingkan skor kesegaran jasmani B sebelum intervensi dan selisih skor kesegaran jasmani B sebelum dan sesudah latihan pada kelompok eksperimen dan kelompok kontrol.

\section{Hasil dan pembahasan}

Berdasarkan tabel 1 distribusi sampel menurut usia pada kelompok kontrol, sampel usia 20 tahun berjumlah 1 orang (5\%), usia 21 tahun berjumlah 3 orang (15\%) dan pada usia 22 tahun berjumlah 1 orang (5\%), usia 23 tahun 4 orang (20\%), usia 24 tahun 1 orang (5\%). Pada kelompok eksperimen, sampel usia 20 tahun berjumlah 3 orang (15\%), usia 21 tahun berjumlah 3 orang (15\%) dan pada usia 22 tahun berjumlah 2 orang (10\%), usia 23 tahun 1 orang (5\%), usia 24 tahun 1 orang (5\%). Sehingga jumlah sampel dalam kelompok kontrol dan kelompok eksperimen adalah 20 orang (100\%).

Hasil analisis statistik skor sebelum intervensi pada kelompok eksperimen dan kelompok kontrol menggunakan independent $\mathrm{T}$ test terdapat perbedaan Mean skor kesegaran jasmani antara kelompok eksperimen (Mean=85.80; $\mathrm{SD}=2.82)$ dan kelompok kontrol (Mean=82.50; $\mathrm{SD}=2.32$ ), dan perbedaan tersebut secara statistik signifikan $(\mathrm{p}=$ 0.011). Dan terdapat perbedaan selisih skor kesegaran jasmani sebelum dan sesudah intervensi antara kelompok eksperimen (Mean= 3.90; $\mathrm{SD}=1.52)$ dan kelompok kontrol $($ Mean $=1.60 ; \mathrm{SD}=0.70)$ dan secara statistik signifikan $(\mathrm{p}<0.001)$, dengan effect size = 
1.94 yang menandakan bahwa latihan core stability benar efektif dalam meningkatkan skor kesegaran jasmani B (tabel 2).

Hasil penelitian berdasarkan peningkatan rata-rata sesudah intervensi dari masing-masing kelompok keduanya mengalami peningkatan, tetapi hasil skor sesudah intervensi pada kelompok eksperimen yang diberikan latihan core stability rata-rata skornya lebih tinggi dari kelompok kontrol. Begitupun selisih skor sebelum intervensi dan sesudah intervensi dari kelompok eksperimen lebih tinggi dibandingkan kelompok kontrol. Hal tersebut dikarenakan melatih otot core di dalam tubuh bisa meningkatkan pola aktivasi otot trunk.

Beberapa penelitian sebelumnya menyatakan bahwa atihan core stability lebih banyak berpengaruh terhadap kestabilan batang tubuh dan kesimbangan (Nourizadeh et al., 2019). Temuan lainnya adalah bahwa 8 minggu Latihan core dapat meningkatkan daya tahan. Hambatan dalam penelitian ini adalah kurangnya jumlah sampel sehingga memengaruhi hasil, juga sampel yang berusia muda dimana di dalam kondisi ketentaraan, sampel masih memiliki kondisi kesegaran jasmani yang baik.

Tabel 1 Distribusi sampel menurut usia

\begin{tabular}{|c|c|c|c|c|c|c|}
\hline \multirow[t]{2}{*}{ Usia } & \multicolumn{6}{|c|}{ Kelompok } \\
\hline & $\mathrm{n}$ & $\%$ & $\mathrm{n}$ & $\%$ & $\mathrm{n}$ & $\%$ \\
\hline 20 & 1 & 5 & 3 & 15 & 4 & 20 \\
\hline 21 & 3 & 15 & 3 & 15 & 6 & 30 \\
\hline 22 & 1 & 5 & 2 & 10 & 3 & 15 \\
\hline 23 & 4 & 20 & 1 & 5 & 5 & 25 \\
\hline 24 & 1 & 5 & 1 & 5 & 2 & 10 \\
\hline JMLAH & 10 & 50 & 10 & 20 & 20 & 100 \\
\hline
\end{tabular}

Tabel 2 Hasil uji t perbedaan mean selisih pretest dan posttest skor kesegaran jasmani antara kelompok eksperimen dan kelompok control.

\begin{tabular}{lcccc}
\hline Kelompok & n & Mean & SD & P \\
\hline Sebelum & & & & \\
intervensi & & 85.80 & 2.82 & 0.011 \\
Eksperimen & 10 & 82.50 & 2.32 & \\
Kontrol & 10 & & & \\
\hline Sebelum & & & & $<0.001$ \\
sesudah & & & 1.52 & \\
intervensi & & 3.90 & 0.70 & \\
Eksperimen & 10 & 1.60 & & \\
Kontrol & 10 & & & \\
\hline
\end{tabular}


Wita Hana Puspita, Tjetjep Sudrajat

\section{Kesimpulan}

Latihan core stability efektif untuk meningkatkan nilai kesegaran jasmani B pada prajurit Yon Armed 4 Cimahi. 


\section{BIBLIOGRAFI}

Az-Zahra, N., Ichsani, F., \& No, J. A. U. (2016). Efektivitas Antara Latihan Kontraksi Eksentrik Hydroterapy Dengan Latihan Ballistic Stretching Untuk Fleksibilitas Otot Hamstring Pada Remaja Putri. Jurnal Fisioterapi, 16(1), 29. Google Scholar

Bae, Jin, Yoon, Kim, Park, \& Lee. (2018). Effects of assisted sit-up exercise compared to core stabilization exercise on patients with non-specific low back pain: A randomized controlled trial. Journal of Back and Musculoskeletal Rehabilitation1, 1-10. Google Scholar

Bliven, K.C., \& Anderson, B.E. (2013). Core Stability Training for Injury Prevention. American Orthopaedic Society for Sport Medicine, 5(6). Google Scholar

Calatayud, Casana, Martin, Jacobsen, Colado, \& Anderson. (2017). Progression of core stability exercises Based on The Extent of Muscle Activity. Am J Phys Med Rehabil, 96, 694-699. Google Scholar

Iskandar, S. A. O. P. (2016). Hubungan psychological well-being dengan komitmen organisasi pada prajurit TNI-AU Lanud Abdulrachman Saleh Malang. University of Muhammadiyah Malang. Google Scholar

Jamalong, A. (2016). Peningkatan prestasi olahraga nasional secara dini melalui pusat pembinaan dan latihan pelajar (PPLP) dan pusat pembinaan dan latihan mahasiswa (PPLM). Jurnal Pendidikan Olah Raga, 3(2), 156-168. Google Scholar

Nourizadeh, S., Mirjani, M., \& Naserpour, H. (2019). The relationship between core stability, muscular endurance, and static balance, and shooting function in military soldiers. Journal of Sport Biomechanics, 5(1), 62-71. Google Scholar

Oliva-Lozano, J. M., Fortes, V., Krustrup, P., \& Muyor, J. M. (2020). Acceleration and sprint profiles of professional male football players in relation to playing position. Plos One, 15(8), e0236959. Google Scholar

Pratama, A. S. G. (2014). Fungsi Lagu dalam Kegiatan Pembinaan Fisik Siang Siswa Skadik 405 Pangkalan TNI AU Adi Soemarmo Solo. INSTITUT SENI INDONESIA (ISI) SURAKARTA. Google Scholar

Putra, D. (2013). Analisis Pembinaan Mental Rohani Islam di TNI AD Komando Daerah Militer (KODAM) Jaya/Jayakarta Cawang. Google Scholar

Saeterbakken, A. H., Steiro, M., \& Navarsete, J. (2015). Muscle Activity, and the Association between Core Strength, Core Endurance and Core Stability. 2, 28-34. https://doi.org/10.17352/2455-5487.000022 Google Scholar

Utami, D. (2015). Peran fisiologi dalam meningkatkan prestasi olahraga Indonesia menuju sea games. Jorpres (Jurnal Olahraga Prestasi), 11(2). Google Scholar 
Wita Hana Puspita, Tjetjep Sudrajat

First publication right:

Jurnal Syntax Fusion: Jurnal Nasional Indonesia

This article is licensed under:

(ㅇ) (1) ( $)$ 